\title{
Time and Form Postponement Competition under Dynamic Behavior of Demand
}

\author{
Yohanes Kristianto, Petri T. Helo \\ University of Vaasa, Department of Production, \\ Logistics System Research Group, PO BOX 700, 65101 Vaasa-Finland \\ Email : yokris@uwasa.fi
}

\begin{abstract}
This paper studies assembly-to-order (form postponement) and make-to-stock (time postponement) duopolistic competition under dynamic price and production strategies for two differentiable products, which share common components at a certain degree of substitution. Both strategies are benchmarked according to the Bertrand and Cournot Stackelberg game. In addition, dynamic game is applied to show the long term effect of both strategic decisions (price and production quantity) on profit and against demand uncertainty. The results show that precommited production is appropriate for high modular products and precommited price for special orders. The final part of the paper concludes the results and outlines future research directions.
\end{abstract}

Keywords: strategic planning, supply chain management, game theory, managerial flexibility, market share, collaborative agents

\section{Introduction}

Price and production capacity are two strategic decisions which product managers face over time. Kreps and Scheinkman (1983) showed that if firms choose capacities before engaging in Bertrand-like price competition, then the Cournot outcome is the result if the given capacities are at Cournot levels, or they should be rationed when the capacity cannot meet market demand. Davidson and Doneckere (1986), however, argued against this investigation and showed that the alternative rationing rule can eliminate idle capacity because the players agree to compete at higher equilibrium capacity.

Because the products undertaken by order-based firms are characterized by uniqueness, uncertainty and complexity, however, the Kreps and Scheinkman or Davidson and Doneckere rationing rules are difficult to apply to this type of firm. One reason is that order-based firms are different from mass production-based firms in many respects. These differences extend to their requirements with respect to product proliferation because consumer preferences are diversified among the available brands (Perloff and Salop, 1985). Since a homogenous product gives no options to consumers and diminish brand loyalty (Klemperer, 1992), most discussions of price or production decision focus on their appropriateness, depending on the single firm demand uncertainty (Miegham and Dada, 1999), while the cooperation between make-to-stock and make-to-order based firm is often considered exogenous (Alptekinoglu and Corbett, 2005), so that such models may underestimate the benefit of product substitutability to represent product's customization (Singh and Vives, 1984; Katz and Shapiro, 1985; Perloff and Salop, 1985; Martin S, 1995; Lambertini et al, 2004; Panchal et al, 2007).

With respect to previous efforts in mass customization investigation, so far, few serious attempts have been made to investigate the effect 
of product substitability degree on make-to-stock and assembly-to-order cooperation by considering the price and production quantity dynamics instead of their values at any given of times. However, the dynamic property is important with regard to the optimum price and quantity decision, at which every player has no reason to change his price or production quantity decision. Our effort in this paper broadly follows Singh and Vives (1984), except that we take into account the possible effects of long term price and production quantity strategic decision, resulting from the presence of order based and stock based firms, and Dr. C.F Ross (1925) in terms of the possible effect of change in the rate of price and production quantity resulting from demand variety. In particular, unlike most of the existing literature on repeated games under product differentiation, we explicitly model those demand uncertainty effects which affect firms' production quantities as well as prices.

In addition to recent literature, the make-to-stock versus make-to-order are represented by two firms is a special case of time and form postponement for a continuous product substitutability distribution. This new approach is quite different to previous methods in the differentiated duopoly game (Singh and Vives, 1984) or price and production postponement (Miegham and Dada, 1999), where the decision is assumed to depend merely on the price or production quantity at any given time, without considering whether the price or production quantity is increasing or decreasing at this time. Even this new approach also quite different to Miegham and Dada (1999), in the light of production and holding costs are assumed under make-to-order or make-to-stock solely, without considering their coexistence under the same product line. Indeed, in order to comprehend price and production contract application to time and form postponement appropriately, we compare Cournot and Bertrand competition in terms of their profitability at several product substitutability degrees and under varied demand.

The following sections first introduce related literature on dynamic analysis in competition, product substitutability in duopoly competition and the research area of this paper (Section 2). Section 3 is started with price (quantity) contract analysis by using the Cournot game model (Section 3.1), which continues with quantity (price) by applying the Bertrand game model (Section 3.2). Section 4 presents and discusses the simulation results, which are concluded in Section 5, which explores the information behind the simulation results in the previous section and discusses some future research opportunities.

\section{Related Literatures}

Dynamic analysis in competition was firstly presented by Dr. C.F Ross (1925) and it was rediscussed further by Smithies and Savage (1940). Dynamic analysis was used to represent a decision maker who intends to plan his capacity in advance according to the present situation. It is clear that production capacity needs long term planning and the paper addresses a problem of two competitors adapting to a new demand function with the goal of profit stability in the future. In contrast, Dudey (1992) argues against both papers by introducing dynamic Edgeworth-Bertrand competition in order to solve dynamic competition under capacity constraint, which causes Nash equilibrium inexistance. The Dudey model assumes that customers come to the market at different times and the firm's price can be reset at any time with an opportunity that at least one of the duopolists can sell all the units it is able to produce. When this game is a duopoly, the payoff function of each firm maps the duopolists' strategy choices into the firm's total expected profit. Even though the Dudey model used dynamic pricing, this model presents price as a short term decision, which can be changed at any time. However, our model posits price and production quantity as two strategic decisions, which are fixed at a certain finite time in order to handle demand change.

Similar to the approaches of Smithies and Savage (1940) or Dudey (1992) on price and quantity, Singh and Vives (1984) focus their analysis on flexible capacity/price appropriateness to hedge against predetermined price/quantity contracts. Their analysis adapts to a new demand or price after making a price or delivery quantity contract formerly under the absence or presence of product substitutability degree. In contrast to that paper, we contribute to this literature by adding dynamic behavior onto the Singh and Vives (1984) duopoly model by analyzing the impact of demand uncertainty on the firm's profitability by applying 
dynamic price or production quantity strategy, which also covers assembly-to-order and make-tostock firm, which have quantity based total costs instead of marginal cost, according to Cournot or Bertrand. In particular, the Cournot duopoly model (Singh and Vives, 1984) is a special case of price contract and the Bertrand duopoly model a special case of production contract. In conclusion, our contribution is focused on the dynamic analysis of the Singh and Vives model (1984). With a different objective to the Smithies and Savage (1940) or Dudey (1940) models, this paper uses dynamic analysis to investigate the price and production quantity postponement effect on supply chain profit.

\section{Introduction to Analytical Model}

Suppose now that two firms must agree on two types of contracts: the price contract and quantity contract. Different to Singh and Vives (1984) use predetermined price or quantity to supply customer demand at any levels, our model uses both types of contracts to maximize supply chain profit. To focus discussion, this paper uses Singh and Vives demands and its reverse function by assuming that both products are perfectly substitutes. Effects of this assumption are products have a sticky price and quantity, which enforces both firms to make long term plan for their price and quantity decision. Both firms however are operated under two different manufacturing strategies, namely make-to-stock (time postponement) and assembly-to-order (form postponement). To gather general understanding for dynamic concept for long term price and quantity strategic decision, both time and form postponement will be discussed separately according to static and dynamic games and then general concept will be developed.

\subsection{Model Description for Dynamic Cournot Game}

In this model we consider a Cournot duopoly model (see Gibbons 1992) with price function for retailers given by

$P(Q)=a-Q$

Where $Q$ is total production quantity from both retailers (retailer 1 and 2), $a$ is maximum acceptable market price. In Cournot game firms choose their own quantity to maximize their profit by taking their opponent's quantity as a given, and in Bertrand game they choose their price to maximize their profit by taking their opponent's price as a given. This means that they are going to sacrifice price in Cournot game and quantity in Bertrand game. We propose thus a methodology to avoid this kind of sacrifice by applying Dynamic Stackelberg game just after quantity has been determined.

To illustrate, we suppose two firms must make two types of contracts, namely price and quantity contracts. If the firms choose form postponement, then they must hedge against production fluctuation as a result of demand uncertainty. In this paper, leader firm chooses time postponement and follower firm chooses form postponement. Firms first choose quantity contract and afterwards they compete on the chosen quantities by considering selling and material prices. Restricting attention to the subgame perfect of this two stage game, we shall see that if leader firm chooses time postponement, then predetermined quantity is used to optimize follower firm quantity, where it is finally used by the both firms to optimize their selling price and production quantity. Both firms do not have any benefits by shifting from their optimum point. From this point on, the game is started from stage 2 , where both retailers decide their capacity.

In this modeling, we define total costs for both of time postponement and form postponement as

$E\left(C_{F P}\right)=\left(h_{2} / 2\right) q_{2}+C_{P} \cdot q_{2} / L T+C_{W} \cdot L+C_{m} q_{2}$

and

$E\left(C_{T P}\right)=C_{O} \cdot q_{1}+h_{1} \frac{q_{1}}{2}+C_{p u r} \cdot q_{1}$

Equation (2) and (3) represent the follower firm (Form Postponement) and the leader firm (Time Postponement) costs function. Follower costs function as a function of its production quantity $q_{2}$ describes that products assembled by putting material inventory $\left(h_{2}\right)$ and production cost $\left(C_{P}\right)$, which is restricted by limited allowable order queue cost $\left(C_{W}\right)$, delivery lead times $L T$, and purchased material order $\left(C_{m}\right)$. On the other hand, leader firm cost function as a function of its production quantity $q_{1}$ describes leader reserves customers by putting 
inventory of ready made products in his show-room $\left(h_{1}\right)$, which is ordered from his supplier at cost $\mathrm{C}_{\mathrm{O}}$ /item and purchased at $\mathrm{C}_{\text {Pur }}$ /item. Symmetric information is assumed in this modeling in order to show contract visibility instead of that the products are produced by the same manufacturer.

\section{Stage 2: Quantity contract optimization}

In this stage follower firm chooses production quantity to maximize his profit, taking leader firm quantity $\left(\mathrm{q}_{1}\right)$ as given. That is, maximize $q_{2}=f\left(q_{1}\right)$, derived from profit equation below

$\operatorname{Max}_{q_{2}}=\left(a-q_{1}-q_{2}-E(C)\right) q_{2}$

Expected costs E(c) in (4) can be referred to (2) as equation (4) is a form postponement profit optimization. Furthermore, demand inter-arrival rate and processing rate is assumed according to $\mathrm{M} /$ $\mathrm{M} / 1$ queue model and total customers in the system can be intrepretated as

$L=\frac{\rho}{1-\rho}$

Where $\rho$ is FP service utilization as a function of FP production rate $\mu$ and customer demand rates $D$. That equation informs us about whether there is a delay/backorder or not in our order. Compete equation for form postponement total costs is composed by incorporating (5) into (2) as follow

$E(C)=\left(C_{m}+\frac{h_{2}}{2}\right) \frac{q_{2}}{2}+C_{p} \cdot \mu+C_{W} \frac{\rho}{1-\rho}$

By combining (4) and (6) and incorporating degree of product substitability (g) so (4) can be modified according to Cournot duopoly inversion (see Singh and Vives, 1984) as follow

$\underset{q_{2}}{\operatorname{Max} \pi_{2}}=\left(\frac{a}{1+\gamma}-\frac{1}{1-\gamma^{2}} q_{1}-\frac{\gamma}{1-\gamma^{2}} q_{2}-\left(\frac{C_{P}}{L T_{2}}+C_{m}+\frac{h_{2}}{2}\right)\right)\left(q_{2}\right)-\left[C_{W} \frac{\rho}{1-\rho}-\right.$

Equation (7) can be optimized against $q_{2}$ by finding its first order condition. Thus, its production quantity can be formulated as
$q_{2}=\frac{\left(1-\gamma^{2}\right)\left(\frac{a}{1+\gamma}-\frac{q_{1}}{1-\gamma^{2}}-\left(\frac{C_{P}}{L T_{2}}+C_{m}+\frac{h_{2}}{2}\right)\right)}{2 . \gamma}$

Equation (8) represents form postponement production quantity by considering leader firm production quantity as given. We see it slope down for the increasing of $q_{1}$.

Since two stage games can solve only individual contract, on the contrary, this game uses production quantity and price contracts consecutively. The reason is we assume that the products are perfectly substitutes. We shall use this upcoming section to make price contract for both firms.

\section{Stage 1 Price contract optimization}

Singh and Vives (1984) use two stages game, which firm will have to supply the amount the consumers demand at a predetermined price or quantity. This paper applies similar principle as Singh and Vives (1984) except that we take into account both the price and quantity at infinite time in order to optimize supply chain profitability resulting from the presence of long term price and production quantity contract. Different to Stackelberg game of Ferstman and Kamien (1987) and Fujiwara (2006), this stage is developed by finding best price response against production quantity decision, which is resulted from Cournot quantity game. This approach avoids price sacrifice as it is naturally shown by Cournot quantity game and it is shown as follow

$\dot{p}(t)=s\left(a-q_{1}-q_{2}-p(t)\right) ; s>0 ; p(0)=p_{0}$

In equation (9) we recognize s as speed of price to go to its optimal value. This speed represents how much time is needed by both firms to negotiate their price contract. This notation finally become insignificant when such a negotiation is done at infinite due date, which both firms are assumed have enough time to analyze their decision. Equation (9) shows how important long term consideration on strategic decision such as price and quantity.

By assuming sticky quantity and prices, then (9) can be reformulated by inserting (8) into (9). Then, a current-value Hamiltonian can be obtained as 
$p_{1}(t)=\lambda s\left(\frac{a}{1+\gamma}-\frac{q_{1}}{2\left(1-\gamma^{2}\right)}-\frac{\left(\frac{a}{1+\gamma}-\left(\frac{C_{P}}{L T_{2}}+C_{m}+\frac{h_{2}}{2}\right)\right)}{2}-p_{1}\right.$

To solve (10), let us set up a current-value Hamiltonian as

$H=\left(p_{1}-\left(C_{O}+\frac{h_{1}}{2}+C_{P u r}\right)\right) q_{1}+\lambda s \dot{p}_{1}$

S.t $(10), q_{1}(t) \geq 0, q_{2}(t) \geq 0$

Where $\lambda$ is per unit change of objective function $\left(\max \pi_{(p)}\right)$ for a small change in $p(t)$. At the following derivation we will recognize $\delta$ as a compound factor, which represents how much penalty cost must be given each time both firms repeat their contract negotiation. This assumption is used to force both firms to achieve a contract agreement as soon as possible. However, this notation finally become insignificant when such a negotiation is done at infinite due date, which both firms are assumed have enough time to analyze their decision. We can prove this insignificancy at the following derivation.

$$
\begin{aligned}
& \frac{\partial H}{\partial q_{1}}=\left(p_{1}-\left(C_{O}+\frac{h_{1}}{2}+C_{P u r}\right)\right)-\frac{\lambda . s}{2\left(1-\gamma^{2}\right)}=0 \\
& \dot{\lambda}_{1}=\delta . \lambda_{1}-\frac{\partial H}{\partial p}=\lambda_{1}(\delta .+s)-q_{1}=0
\end{aligned}
$$

Steady state price can be found from (12) and (13) by setting time as infinite $(s \rightarrow \propto$ )

$$
\lim _{s \rightarrow \infty} p_{1}=\left(C_{O}+\frac{h_{1}}{2}+C_{P u r}\right)+\frac{q_{1}}{2\left(1-\gamma^{2}\right)}
$$

By inserting (8) into Cournot duopoly inversion, then $p_{l}$ can be reformulated as
$p_{1}=\frac{a}{1+\gamma}-\frac{q_{1}}{2\left(1-\gamma^{2}\right)}-\frac{\left(\frac{a}{1+\gamma}-\left(\frac{C_{P}}{L T_{2}}+C_{m}+\frac{h_{2}}{2}\right)\right)}{2}$

Solve (14) and (15) simultaneously and finally leader optimum price and quantity can be stated as

$q_{1}=\left(1-\gamma^{2}\right) \frac{a}{1+\gamma}-\frac{\left(\frac{a}{1+\gamma}-\left(\frac{C_{P}}{L T_{2}}+C_{m}+\frac{h_{2}}{2}\right)\right)}{2}-\left(C_{O}+\frac{h_{1}}{2}+C_{P_{u r}}\right)$,

With the same way, $p_{2}$ could be obtained as

$p_{2}=\left(\frac{C_{P}}{L T_{2}}+C_{m}+\frac{h_{2}}{2}\right)$

\subsection{Model Description for Dynamic Betrand Game}

In this model we consider a Cournot duopoly model (see Gibbons 1992) with price function for retailers given by

$Q=b-p_{i}+\gamma \cdot p_{j}$

Where $Q$ is total production quantity from both retailers (retailer 1 and 2), $b$ is total market size, and $p_{i}$ and $p_{j}$ is price of product 1 and 2 .

In the Bertrand game both firms choose their own price to maximize their profit simultaneously by taking product substitutability degree as a given. We thus propose a methodology which is similar to the previous Cournot game, except that we take into account the quantity at infinite time in order to optimize the postponed decision resulting from the presence of long term quantity contract.

Since two-stage games can solve only an individual contract, this game uses product price and quantity contracts consecutively. The reason is we assume that the products are perfect substitutes. 
Stage 2 Follower decide his price according to leader price

$$
\max _{p 2}\left(b-p_{2}+\gamma \cdot p_{1}\right)\left(p_{2}-\left(\frac{h_{2}}{2}+\frac{C_{P}}{L T}+C_{m}\right) q_{2}-C_{W} \cdot L\right)
$$

Solving that equation for $p_{2}$ and by finding relationship of $b+\gamma \cdot p_{1}=q_{2}+p_{2}$, one can obtain

$p_{2}=\frac{\left(\frac{h_{2}}{2}+\frac{C_{P}}{L T}+C_{m}+1\right) \cdot\left(b+\gamma \cdot p_{1}\right)+C_{W} \cdot L}{\left(2+\frac{h_{2}}{2}+\frac{C_{P}}{L T}+C_{m}\right)}$

Stage 2 explores price equilibrium between two buyers. This equation shows effort to maximize standard platform utilization by increasing product substitutability value. Furthermore both prices are used to decide production quantity as follow

\section{Stage 1 Capacity postponement decision}

Singh and Vives (1984) use two stages game, which firm will have to supply the amount the consumers demand at a predetermined price or quantity. This paper applies similar principle as Singh and Vives (1984) except that we take into account both the price and quantity at infinite time in order to optimize supply chain profitability resulting from the presence of long term price and production quantity contract. Different to Stackelberg game of Ferstman and Kamien (1987) and Fujiwara (2006), this stage is developed by finding best price response against price decision, which is resulted from Bertrand pricing game and it is shown as follow

$q(t)=s(q-q(t)) ; s>0 ; q(0)=q_{0}$

In equation (21) we recognize $s$ as speed of quantity to go to its optimal value. This speed represents how much time is needed by both firms to negotiate their quantity contract. This notation finally become insignificant when such a negotiation is done at infinite due date, which both firms are assumed have enough time to analyze their decision. Equation (21) shows how important long term consideration on strategic decision such as price and quantity.
To solve (21), let us set up a current-value Hamiltonian as

$$
H_{1}=q_{1} \cdot p_{1}+\lambda_{1} s\left(a-p_{1}+\gamma \cdot p_{2}-q_{1}\right)
$$

$$
\text { S.t }(21) q(t) \geq 0
$$

Where $\lambda$ is per unit change of objective function ( $\max \pi_{(q)}$ ) for a small change in $q(t)$. At the following derivation we will recognize $\delta$ as a compound factor, which represents how much penalty cost must be given each time both firms repeat their contract negotiation. Similar to Dynamic Cournot game, leader optimum price and quantity can be stated

$p_{2}=\frac{b+\gamma \cdot p_{1}+\left(\left(\frac{h_{2}}{2}+\frac{C_{P}}{L T}+C_{m}\right) \cdot q_{2}+C_{W} \cdot L\right)}{2}$

$q_{2}=b-\frac{\left(\frac{h_{2}}{2}+\frac{C_{P}}{L T}+C_{m}+1\right) \cdot\left(b+\gamma \cdot p_{1}\right)+C_{W} \cdot L}{\left(2+\frac{h_{2}}{2}+\frac{C_{P}}{L T}+C_{m}\right)}+\gamma \cdot p_{1}$

We can see that equilibrium quantity and price is a concave function of product substitability $(\gamma)$. In conclusion, this parameter gives positive impact to supplier-buyer join product development since the increasing of substitutability degree also increases supply chain profitability.

Below, Static Cournot and Bertrand game are given to illustrate the advantage of dynamic Cournot and Bertrand Stackelberg games as follow.

\subsection{Static Cournot and Bertrand Game}

\subsubsection{Static Cournot Game}

In this section, a static Cournot Stackelberg game is derived in order to compare with the above dynamic Cournot Stackelberg game. Let us start it by utilizing equation (8) into (3) as follow in equation (25) 


$$
\underset{\substack{q_{1} \\ q_{1}}}{\operatorname{Max}}=\left(a-\frac{\gamma\left(1-\gamma^{2}\right)\left(\frac{a}{1+\gamma}-\frac{q_{1}}{1-\gamma^{2}}-\left(\frac{C_{P}}{L T_{2}}+C_{m}+\frac{h_{2}}{2}\right)\right)}{2 . \gamma\left(1-\gamma^{2}\right)}-\frac{q_{1}}{\left(1-\gamma^{2}\right)}-\left[C_{O}+C_{P_{u r}}+\frac{h_{1}}{2}\right]\right)\left(q_{1}\right)
$$

By optimizing (25) then we find $q_{1}$ as

$$
q_{1}=\left(1-\gamma^{2}\right) a-\frac{\gamma\left(1-\gamma^{2}\right)\left(\frac{a}{1+\gamma}-\left(\frac{C_{P}}{L T_{2}}+C_{m}+\frac{h_{2}}{2}\right)\right)}{2 \gamma\left(1-\gamma^{2}\right)}-\left[C_{o}+C_{P u r}+\frac{h_{1}}{2}\right]
$$

insert (8) and (26) into Cournot duopoly inversion (see Singh and Vives, 1986) the $p_{1}$ and $p_{2}$ are simply calculated according to

$$
\begin{aligned}
& P_{1}=\frac{a}{1+\gamma}-\frac{1}{1-\gamma^{2}} q_{1}-\frac{\gamma}{1-\gamma^{2}} q_{2} \\
& P_{2}=\frac{a}{1+\gamma}-\frac{\gamma}{1-\gamma^{2}} q_{1}-\frac{1}{1-\gamma^{2}} q_{2}
\end{aligned}
$$

\subsubsection{Static Bertrand Game}

In this section, a static Cournot Stackelberg game is derived in order to compare with the above dynamic Stackelberg game. Let us start it by utilizing equation (8) into (4) as follow

$$
\underset{P_{1}}{\operatorname{Max} \pi_{1}}=\left(b+\gamma \frac{\left(\frac{h_{2}}{2}+\frac{C_{P}}{L T}+C_{m}+1\right) b+C_{W} \cdot L}{\left(2+\frac{h_{2}}{2}+\frac{C_{P}}{L T}+C_{m}\right)}+\left(\frac{\gamma^{2}\left(\frac{h_{2}}{2}+\frac{C_{P}}{L T}+C_{m}+1\right)}{\left(2+\frac{h_{2}}{2}+\frac{C_{P}}{L T}+C_{m}\right)}-1\right) p_{1}-\left[C_{O}+C_{P_{u r}}+\frac{h_{1}}{2}\right]\right)\left(p_{1}\right)
$$

By optimizing (29) for $p_{1}$, one obtains

$$
p_{1}=\frac{\left(b+\gamma \frac{\left(\frac{h_{2}}{2}+\frac{C_{P}}{L T}+C_{m}+1\right) b+C_{w} \cdot L}{\left(2+\frac{h_{2}}{2}+\frac{C_{P}}{L T}+C_{m}\right)}-\left[C_{O}+C_{P_{u r}}+\frac{h_{1}}{2}\right]\right)}{\left(2-\frac{2 \gamma^{2}\left(\frac{h_{2}}{2}+\frac{C_{P}}{L T}+C_{m}+1\right)}{\left(2+\frac{h_{2}}{2}+\frac{C_{P}}{L T}+C_{m}\right)}\right)}
$$

Insert (30) into (20) and use both of them into (8), then, $q_{1}$ and $q_{2}$ are simply calculated according to

$$
\begin{aligned}
& q_{1}=b-p_{1}+\gamma \cdot p_{2} \\
& q_{2}=b-p_{2}+\gamma \cdot p_{1}
\end{aligned}
$$


Figure 1 Static and dynamic Bertrand game profit comparison

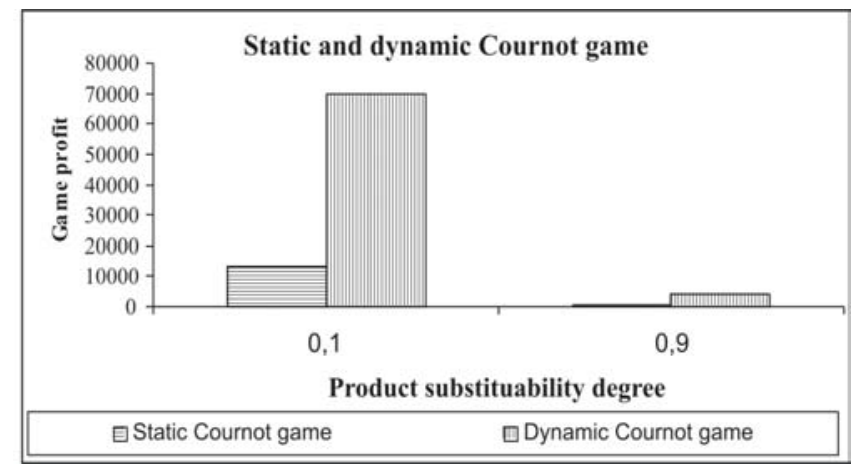

Figure 2 Static and dynamic Cournot game profit comparison

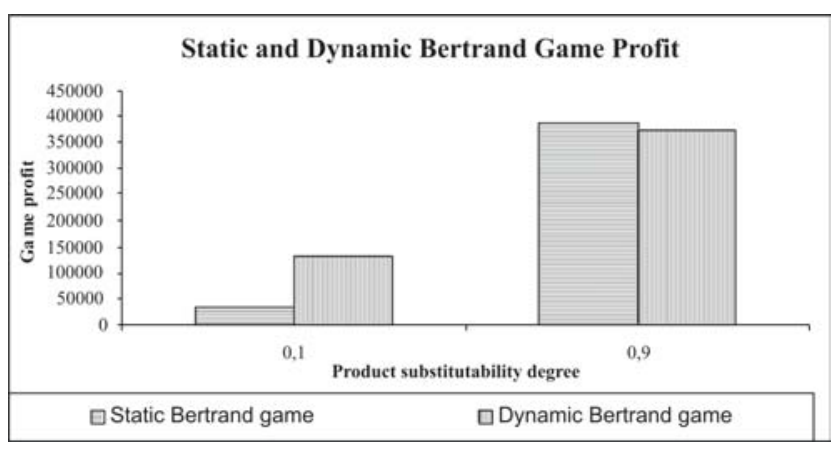

Furthermore, dynamic game gives more opportunities to be applied at higher substitutability degree gives more opportunity to (see Figure 2).

To examine the case with erratic demands, suppose firms strictly predetermine their price and quantity settings, which is strictly revised in their profitability. Now if we randomizeorvalue to represent demand variety, then we get $\pi_{(p)} \pi_{(q)}$ or as a function of $q, p$ and $\gamma$; hence, the results can be drawn as in figure 3 and 4 .

Figure 3 and 4 clearly show that dynamic production contract game (Cournot game) is more favourable at high substitutable products at varied demands, which is shown by least fluctuations than price contract (Bertrand game) at high product substitutability degree (please compare its fluctuation according to $\gamma=0,1$ and $\gamma=0,9)$. These results again ensure that long term decision on how many to produce is appropriate at higher compatible products instead of how much the price at less compatible product.

We know that profit stability is a common goal of price and production quantity contracts. High profit stability ensures two firms can cooperate
Figure 3 Static and dynamic Cournot and Bertrand game profit at varied demand at low product substitutability $(\gamma=0,1)$

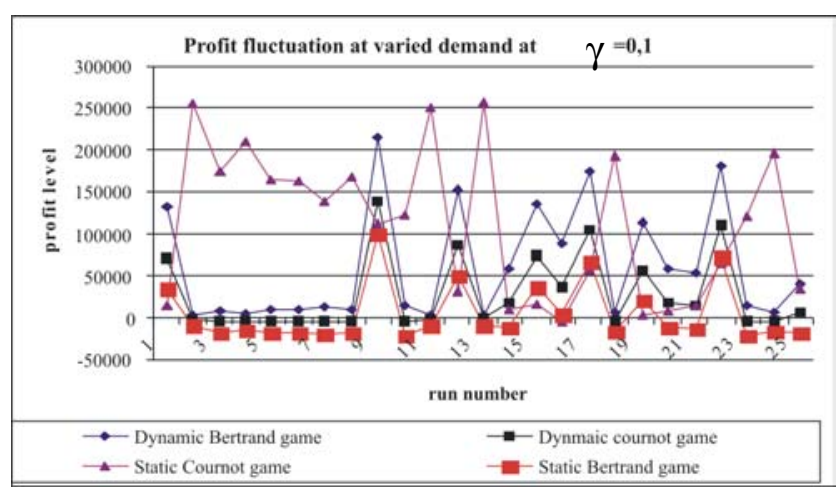

Figure 4 Static and dynamic Cournot and Bertrand game profit at varied demand at high product substitutability $(\gamma=0,9)$

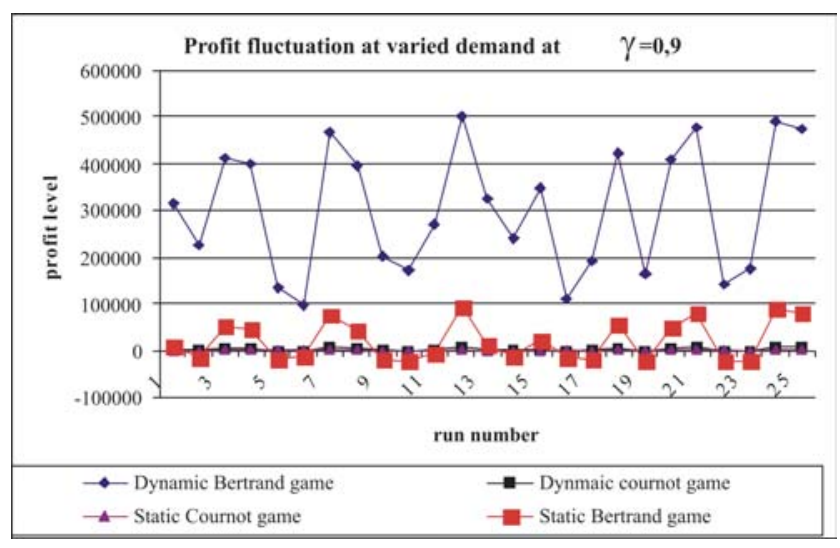

without worrying about any losses. Below is a comparison between two games types, which is gathered by finding profit at different price or quantity settings. Now if we measure their deviation from optimum profit value (replace $q$ or $p$ by our own assumption), then we get $\pi_{(p)}$ or $\pi_{(q)}$ as a function of $q, p$ and $\gamma$. Benchmarking them against optimal value, the results are shown in figures 5 and 6 .

Figure 5 and 6 clearly show that dynamic production contract game (Cournot game) is more favourable at at varied demands, which is shown by less deviation than price contract (Bertrand game) at high product substitutability degree (please compare its fluctuation according to $\gamma=0,1$ and $\gamma=0,9$ ). These results again ensure that long term decision on how many to produce is appropriate at higher demand variety. 
Figure 5 Static and dynamic Cournot and Bertrand game profit dynamics at varied demand at low product substitutability $(\gamma=0,1)$

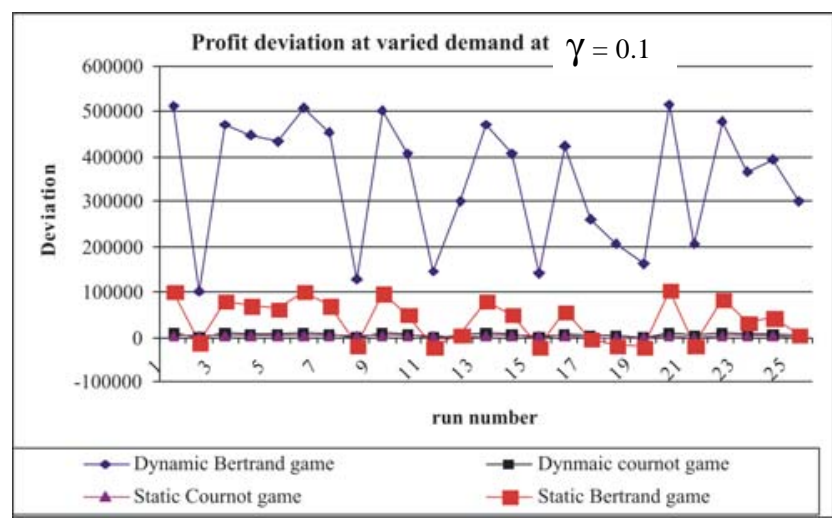

Figure 6 Static and dynamic Cournot and Bertrand game profit dynamics at varied demand at high product substitutability $(\gamma=0,9)$

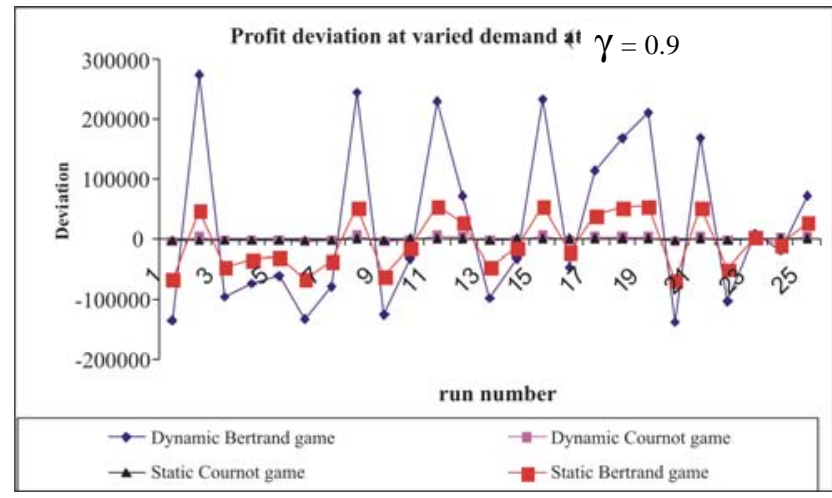

In addition to the managerial implication, dynamic stackelberg game is also significantly superior to static Cournot game from the customer service level point of view (see Figure 5). That figure shows that the proposed game can cover market demand at a higher level than static Cournot game. This result supports the managerial policy of product commonality, where price can be determined later after final customization is completed.

Furthermore, dynamic Stackelberg game is still superior over static Cournot game at a higher product substitutability degree. This result once more supports the view that static Cournot game is only appropriate to highly unique products. The reverse result is shown for dynamic Stackelberg game, where firms develop a common platform to maximize profit.

\section{Conclusion and Further Research}

This paper revisited the Singh and Vives model on price and production predetermined contract by considering the dynamic behavior of demands onto make-to-stock and assembly-to-order competition. We may summarize the results derived from the model, as follows.

1. Production contract is superior to price contract at many respects. This type of contract guarantees profit stability and at the same time supports the product standardization effort

2. Production quantity contract is also a dominant strategy for substitutable products. This conclusion is at odds with the previous Singh and Vives conclusion (Singh and Vives, 1984). This discrepancy is caused by the Singh and Vives model perhaps assuming that in Bertrand price-like competition, the quantity setting will avoid both firms having to reduce their production quantity further. On the contrary, this paper assumes sticky prices and quantities, where it pushes both firms to cooperate at higher levels. By sticky prices and quantities, this paper is more appropriate for common platform based products instead of two widely differentiated products.

3. Price contract is a dominant strategy for highly differentiable products of make-to-stock and assembly-to-order competition. This conclusion supports the article of Miegham and Dada (1999), who discusses postponement strategies differentiation according to their applicability.

The dynamic behavior analysis in this paper helps decision makers to decide their long term price and production quantity policy with regard to their manufacturing types, namely make-to-stock and assembly-to-order. The analysis results also support both modularity and customization principles in mass customized products, where decision uncertainty can be reduced by making closer customer order decoupling, point of sales. This paper suggests product developers to design common platform products and decide the price according to customer specific requirements.

In terms of future research direction, the oligopoly model should be considered for development according to future market demand, 
which is determined by how close customer requirements are met, so in future the oligopoly model quantity and price can be replaced with some parameters such as inventory and lead times. From this result, a sequence between lead times and inventory can be determined and the outcome will be a decision about whether agility or efficiency is more important for a company, so that the outcome can be used by top management to compose their business strategy. Finally, future research should accommodate strategic and tactical level alignment in order to develop comprehensive decision analysis.

\section{References}

Alptekinoglu, A and Corbett, C.J, (2005), Mass customization versus mass production: price and variety competition. http://repositories.cdlib.org/cgi/ viewcontent.cgi?article $=1050 \&$ context=anderson/dotm. Accessed:5 January 2008.

Davidson, C., and Deneckere, R. (1986).Long-run competition in capacity, short-run competition in price, and the Cournot model.Rand Journal of Economics, 17, pp. 404-415.

Dudey, M. (1992).Dynamic Edgeworth-Bertrand competition. The Quarterly Journal of Economics, 107 (4), pp. 1461-1477.

Fershtman, C., and Kamien, M.I.(1987).Dynamic duopolistic competition with sticky prices. Econometrica, 55(2), pp. 1151-1164.

Fujiwara, K.,(2006).A Stackelberg game model of dynamic duopolistic competition with sticky prices.Economic Bulletin, 12(12).pp. 1-9.

Gibbons, R., (1992), A Primer in Game Theory,Pearson Education Limited.
Katz, M.L., and Shapiro, C.(1985). Network Externalities, Competition, and Compatibility.The American Economic Review, 75 (3), pp. 424-440.

Klemperer, P. (1992). Equilibrium Product Lines: Competiting Head to Head May be Less Competitive.The American Economic Review, pp. 82 (4), 740-755

Kreps, D., and Scheinkman, J.(1983). Quantity precommitment and Bertrand competition yield Cournot outcomes. Bell Journal of Economics, 14, pp. 326-337.

Lambertini, L., and Mantovani, A.(2004). Process and Product Innovation.A Differential Game Approach to Product Life Cycle. http://www2.dse.unibo.it/seminari/ Mantovani, Accessed: 5 January 2008.

Martin S, (1995). R \& D joint ventures and tacit product market collusion. European Journal of Political Economy, 11, pp. 733-741.

Miegham, J.A.V and Dada, M, (1999).Price versus Production Postponement: Capacity and competition. Management Sciences, 45(12), pp. 1631-1649.

Panchal, J.H, Fernandez, M.G, Paredis, C.J.J, Allen, J.K and Mistree, F.(2007).An Interval-based Constraint Satisfaction (IBCS) Method for Decentralized, Collaborative Multifunctional Design, Concurrent Engineering.Research and Application, 15(3), pp. 309-323.

Perloff, J, M. and Salop, S, C.(1985).Equilibrium with Product Differentiation.The Review of Economic Studies, 52 (1), pp. 107-120.

Ross, C, F.(1925).A Mathematical Theory of Competition. American Journal of Mathematics, 47 (3). pp. 163-175.

Singh, N. and X. Vives.(1984).Price and quantity competition in a differentiated duopoly, Rand Journal of Economics, 15. pp. 546-554.

Smithies, A., and Savage, L, J. (1940).A Dynamic problem in duopoly.Econometrica,8 (2). pp. 130-143.

Spence, M, (1976). Product Differentiation and Welfare, The American Economic Review, 66 (2). Papers and Proceedings of the Eighty-eighth Annual Meeting of the American Economic Association, pp. 407-414.

Yohanes Kristianto is now a PhD student in Industrial Management at University of Vaasa, Finland. His research interests are in the area of supply-chain strategy/management and production/operations management. His papers has been published several international journals. Email address: yokris@uwasa.fi

Petri. T. Helo is currently professor in the Department of Production, University of Vaasa, Finland. His major research interest addresses the management of logistics processes in supply demand networks, which take place in electronics, machine building and food industries. This research has developed new approaches on analytical modelling and use of computers solving industrial management problems. His research interest includes logistics systems and supply chain management, information technology tools and productivity measurement and technology progress. His works have been published in various journals, including the International Journal of Advanced Manufacturing Technology, International Journal of Manufacturing Technology and Management, International Journal of Management and Enterprise Development, International Journal of Production Research, International Journal of Agile Management System, International Journal of Innovation and Learning etc. 